\title{
Effect of corticotrophin therapy on pituitary-adrenal function
}

\author{
MARY E. CARTER AND V. H. T. JAMES \\ From St. Mary's Hospital and the Department of Chemical Pathology, St. Mary's Hospital Medical School, \\ London
}

There is now an extensive literature which describes the effects of corticosteroid therapy on hypothalamicpituitary-adrenal function. These investigations have shown a diminished adrenal responsiveness to corticotrophin and impaired responses to metyrapone in patients receiving corticosteroids (see for example Landon, Wynn, James, and Wood, 1965; Treadwell, Savage, Sever, and Copeman, 1963; Livanou, Ferriman, and James, 1967; Daly, Myles, Bacon, Beardwell, and Savage, 1967; Jasani, Boyle, Greig, Dalakos, Browning, Thompson, and Buchanan, 1967, and references in these papers). Although all the factors which are involved in this process are still undetermined, and various patients undoubtedly show individual susceptibility, it is likely that the dose level employed, duration of treatment, and total amount of steroid administered are all important considerations. Whilst the exact mechanism is undefined, it is widely accepted that failure to produce an elevation of the plasma cortisol level in response to certain stressful situations may lead to a hazardous metabolic state which may occasionally prove fatal. Since long-term steroid administration is often required in the treatment of various diseases, these considerations become particularly important when patients are exposed to infection or surgery, or when treatment is terminated.

As an alternative to corticosteroid therapy, treatment with corticotrophin has been employed, and has proved therapeutically effective. There is, however, relatively little published work on the effect of this form of treatment on pituitary-adrenal function, and such studies as are available have revealed conflicting results. Thus, some investigators have found that treatment with ACTH produces similar effects to corticosteroid therapy, arid have observed diminished pituitary-adrenal responsiveness (Solem and Brinck-Johnson, 1961; Plager and Cushman, 1962), but others have reached the opposite conclusion (Bacon, Daly, Myles, and Savage, 1968). It appears likely that, as with corticosteroids, individual variability between patients may be involved, and also that the duration of treatment and previous steroid therapy may be important factors. The purpose of the present study is therefore to try to define the effect of ACTH therapy on pituitary-adrenal function, and in particular, emphasis has been laid upon the results of tests designed to assess responsiveness to stress. In addition, observations have been made regularly throughout extended periods of therapy to observe possible alterations in response through the treatment period.

\section{Material and Methods}

Fourteen patients, eight women and six men, were studied. Thirteen have classical rheumatoid arthritis according to the criteria of the American Rheumatism Association (Ropes, Bennett, Cobb, Jacox, and Jessar, 1959), and one has psoriatic arthropathy. Their ages range from 13 to 70 years (mean 51), and the mean duration from onset of the disease is 9 years (range 1 to 26).

The patients were divided into two groups:

GROUP I Seven patients who had not had previous treatment with corticotrophin or corticosteroids, and one who had received $5 \mathrm{mg}$. prednisolone daily for less than a year. Since this treatment had been discontinued more than a year before he entered this series, it was thought appropriate to include him in this group.

GROUP II Six patients who had been treated with systemic steroids up to the beginning of this study for periods ranging from 3 months to 10 years, the doses 
of prednisolone (or equivalents) ranging from 5 to $15 \mathrm{mg}$. daily.

All patients have active disease of considerable severity, and each has had a preliminary period of intensive treatment with antirheumatic drugs other than corticosteroids or corticotrophin, as well as other appropriate supportive measures. None was submitted to corticotrophin or corticosteroid treatment until these other means had proved inadequate to enable them to manage independently. At the start of corticotrophin therapy each patient was admitted to hospital for an initial period of approximately 4 weeks for clinical assessment before and after starting corticotrophin, in order to determine the appropriate dose, and to deal with any early problems arising from its administration. During this time data were obtained on the duration of action of various corticotrophin preparations and on the plasma and urinary steroid levels produced. All the corticotrophin preparations were clinically acceptable, and although they have slightly different lengths of action there was no detectable difference in therapeutic efficiency, nor any indication that the differing lengths of action showed a disadvantageous effect on pituitary-adrenal function. Patients have since been seen regularly for re-assessment and for repeated tests of pituitary-adrenal function.

The corticosteroid used was enteric-coated prednisolone 'Delta Cortril' (Pfizer), and various types of corticotrophin were given: 'Acthar Gel' (Armour), 'ACTH/cmc' (Crookes), 'Cortrophin ZN' (Organon), and 'Cortrosyn' (Organon). In every case the intramuscular route was used.

\section{Insulin stress test \\ Of the available indicators of response to stress in the human subject, the adrenal response to insulin-induced hypoglycaemia is probably the most meaningful and clinically acceptable. Soluble insulin (0.15 u./kg. body- weight) is administered intravenously to the fasting patient, in order to produce hypoglycaemia of $40 \mathrm{mg}$./ $100 \mathrm{ml}$. or less, and this acts as a metabolic stress to the pituitary-adrenal system, which is revealed by an increase in blood cortisol, samples being taken before the insulin is given and at 30-minute intervals afterwards for 2 hours (Greenwood, Landon, and Stamp, 1966).}

\section{Lysine vasopressin test}

This was carried out as described elsewhere (Brostoff, James, and Landon, 1968) using 10 p.u. lysine-8vasopressin, given intramuscularly.

\section{Plasma cortisol}

This was estimated by an automated fluorimetric technique (Townsend and James, 1968).

\section{Results}

GROUP I (patients who had not previously received corticosteroid therapy)

Fig. 1 shows the results of insulin stress tests carried out at intervals in the eight patients receiving daily corticotrophin. The charts for each individual patient show the resting level of plasma cortisol and the maximum level attained during hypoglycaemia, connected by a line. Additionally, the dose of corticotrophin and the number of weeks of continuous daily treatment is shown respectively below and above each graph. We have taken as criteria for a normal test a resting plasma cortisol level of at least $5 \mu \mathrm{g}$. $/ 100 \mathrm{ml}$., an increment of at least $7 \mu \mathrm{g} . / 100 \mathrm{ml}$., and a maximum stimulated level of at least $20 \mu \mathrm{g} . / 100 \mathrm{ml}$.

The results fall into two groups. In five patients (I, II, III, IV, and V), no abnormality in the test criteria was seen at any time, even after 81 weeks' continuous treatment in one (Case IV).

In the other three patients (VI, VII, and VIII), only minor differences from normality were found in VI and VII, who showed occasional low resting levels, or responses which were marginally below that reached by healthy controls. Patient VIII, however, showed an entirely different response pattern. This is a 13-year-old boy who has had rheumatoid arthritis for 10 years and has received daily intramuscular injections of 30 units corticotrophin (Acthar Gel) for over 2 years, during which time he has grown $12 \mathrm{~cm}$. The first insulin test had to be delayed until he had been on corticotrophin treatment for 4 months and this shows an impaired response, as does the one following. Thereafter, with no change in treatment, he achieved normal responsiveness to hypoglycaemic stress and has maintained it to the present.

GROU P II (patients who had been receiving corticosteroids up to the time of starting corticotrophin)

The results of the tests on the six patients in this group are shown in Fig. 2.

Stress tests carried out immediately after stopping corticosteroids gave abnormal results in all but one patient (III) and those on the higher doses showed the most marked suppression. Five of the six patients (I, II, III, IV, and V) showed normal or marginally subnormal results at all times throughout the period of study. Patient VI showed variable results; on some occasions, excellent responses were obtained, whilst on others, the response was significantly depressed.

\section{Lysine vasopressin tests}

Tables I and II show a comparison, in the two groups of patients, of the results of the insulin stress test (IST) and the lysine vasopressin (LVP) test. In studies reported elsewhere (Brostoff and others, 1968), the normal plasma cortisol response 

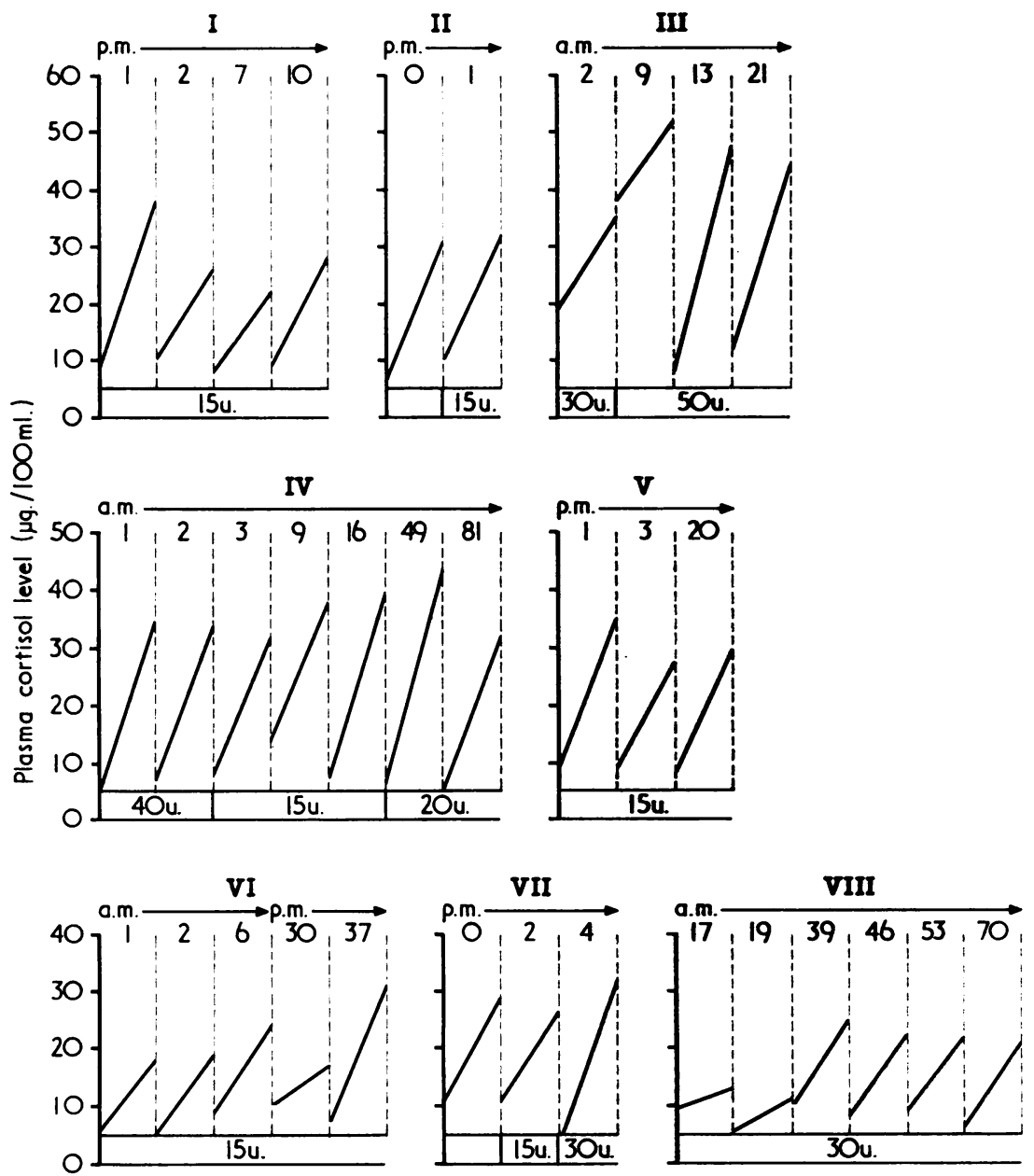

FIG. 1 Group I. Serial plasma cortisol responses to insulin hypoglycaemia in eight patients receiving daily intramuscular injections of ACTH (doses expressed as international units/day at the foot of each graph).

Oblique lines show maximum increment in plasma cortisol for each test in $\mu \mathrm{g} . / 100 \mathrm{ml}$. (ordinate). Tests were carried out at intervals, shown at top of each graph in weeks. Morning or evening administration is also indicated.

to LVP was determined as an increment of at least $5 \mu \mathrm{g} . / 100 \mathrm{ml}$., reaching a level of at least $16 \mu \mathrm{g} . /$ $100 \mathrm{ml}$.

The Tables illustrate the variable response to LVP found in these patients. In some patients (e.g. VIII in Table I), both insulin and LVP elicited a good normal response when both tests were carried out. In other patients (e.g. I in Table I) the normal insulin response was associated with markedly sub-normal responses to LVP. In one patient (V in Table II)) a negative response to LVP subsequently reverted to normal. Thus, no consistent pattern was seen.

\section{Discussion}

Employing the test stimulus of insulin-induced hypoglycaemia as an index of responsiveness of the hypothalamic-pituitary-adrenal (HPA) system, it was found that, with one exception, none of the patients who had received daily corticotrophin therapy showed any marked degree of suppression. In this one patient, HPA suppression occurred during the first few months of ACTH treatment, but, for reasons which are not apparent, this disappeared later without change of treatment. None of the other patients studied showed this phenomenon, although slight variations in response 


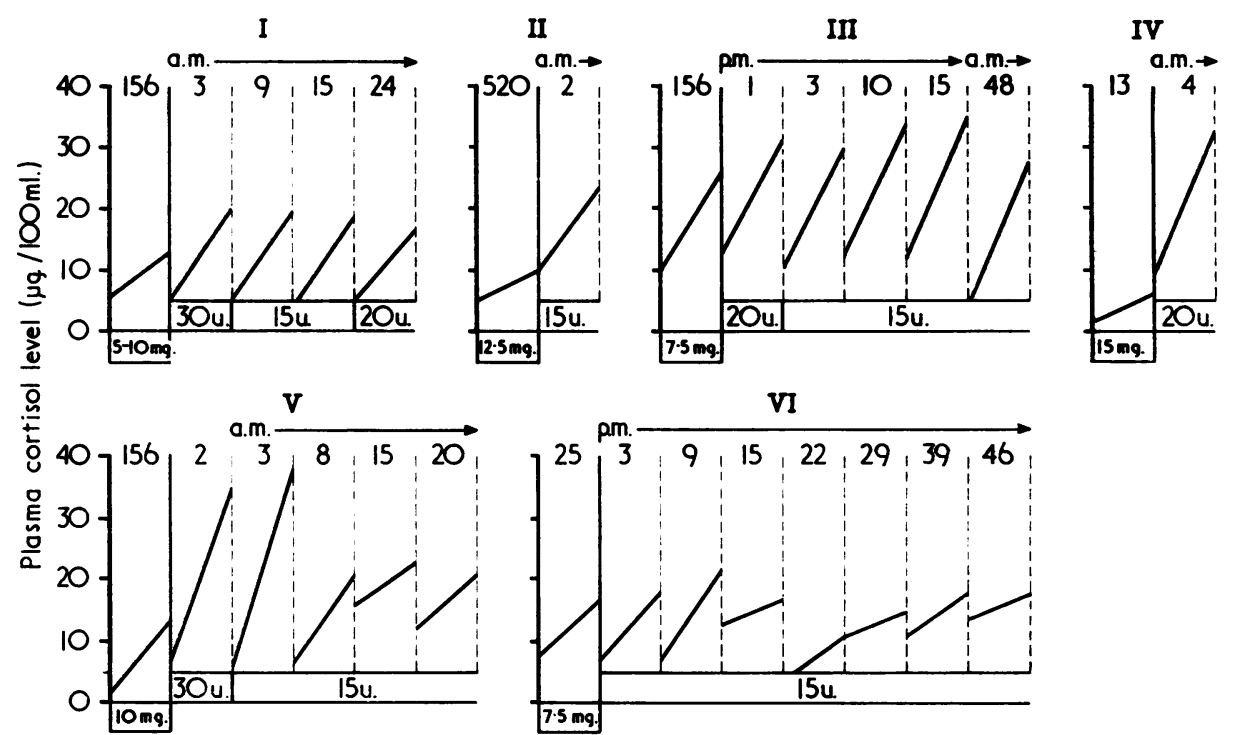

FIG. 2 Group II. Serial plasma cortisol responses to insulin hypoglycaemia in six patients receiving daily intramuscular injections of ACTH (doses expressed as international units/day at the foot of each graph).

Oblique lines show maximum increment in plasma cortisol for each test in $\mu \mathrm{g} . / 100 \mathrm{ml}$. (ordinate). The first test shown in each graph was performed immediately after discontinuing steroid therapy, the average dose of steroids being given below in $\mathrm{mg}$./day and the duration of steroid treatment above in weeks.

After stopping the steroids and starting the ACTH, tests were carried out at intervals, shown at the top of each graph in weeks. Morning or evening administration is also indicated.

occurred from time to time. These investigations were made intentionally over extended periods of time to ascertain whether changes in the responsiveness of the HPA axis occurred; some of these patients have now been treated continuously with daily ACTH for more than 2 years and throughout this period have maintained excellent responses to hypoglycaemia.

These findings clearly contrast markedly with the results seen in patients treated with corticosteroids. Suppression of HPA function occurs in a high proportion of these patients, depending on the dose and duration of treatment, and this has been well demonstrated by several groups of investigators.

Results of previous investigations of the effect of long-term ACTH treatment on HPA function have not been concordant, and it is not apparent why discrepancies exist. Using metyrapone to examine pituitary responsiveness, Plager and Cushman (1962) found a considerably diminished response in six subjects given ACTH twice daily for 3 days, and Solem and Brinck-Johnson (1961) concluded that metyrapone response was depressed by treatment with ACTH twice daily for 2 days. Other authors, studying patients treated for longer periods with daily ACTH, have only exceptionally found impairment of the response to metyrapone
(Savage, Copeman, Chapman, Wells, and Treadwell, 1962; Holub, Wallace, and Jailer, 1960). In an extensive study, Bacon and others (1968) also found that patients receiving long-term daily injections of ACTH retained in almost all cases a satisfactory response to hypoglycaemia although four of their patients produced subnormal responses.

The consensus of opinion, therefore, is in agreement with our own findings, that patients receiving long-term daily single injections of ACTH almost invariably retain HPA responsiveness, at least as judged by stimulation with insulin-induced hypoglycaemia. However, in many patients on ACTH therapy, it is clear that some abnormality of function is present because responses to lysine-8-vasopressin are not consistently normal. There was no correlation when we compared results of insulin stress tests with those of lysine-8-vasopressin tests performed at almost the same time on each patient. Further discussion of these results is probably unprofitable at present, since we lack complete understanding of the mode of action of lysine vasopressin in causing ACTH release. It now appears unlikely that this substance acts directly on the anterior pituitary gland as a corticotrophin-releasing factor, and its effects may require hypothalamic participation. In this case, the dissociation of responses to 
Table I Results of serial insulin (IST) and lysine vasopressin (LVP) tests in eight patients treated with ACTH, without previous corticosteroid therapy

\begin{tabular}{|c|c|c|c|c|c|c|c|c|}
\hline Patient & Test & \multicolumn{7}{|c|}{ Period on ACTH (wks) } \\
\hline \multirow{3}{*}{ I } & \multirow{3}{*}{$\begin{array}{l}\text { IST } \\
\text { LVP }\end{array}$} & 1 & 2 & 7 & 10 & & & \\
\hline & & $+29(9-38)$ & $+16(10-26)$ & $+14(8-22)$ & $+19(9-28)$ & & & \\
\hline & & $-1(8-7)$ & $+2(5-7)$ & $+1(5-6)$ & & & & \\
\hline \multirow{3}{*}{ II } & \multirow{3}{*}{$\begin{array}{l}\text { IST } \\
\text { LVP }\end{array}$} & $\mathbf{0}$ & 1 & & & & & \\
\hline & & $+24(7-31)$ & $+22(10-32)$ & & & & & \\
\hline & & & $-2(11-9)$ & & & & & \\
\hline \multirow{2}{*}{ III } & \multirow[b]{2}{*}{ IST } & 2 & 9 & 13 & 21 & & & \\
\hline & & $+16(19-35)$ & $+14(38-52)$ & $+40(8-48)$ & $+32(12-44)$ & & & \\
\hline \multirow{3}{*}{ IV } & \multirow{3}{*}{$\begin{array}{l}\text { IST } \\
\text { LVP }\end{array}$} & 1 & 2 & 3 & 9 & 16 & 49 & 81 \\
\hline & & $+30(5-35)$ & $+27(7-34)$ & $+24(8-32)$ & $+24(14-38)$ & $+33(7-40)$ & $+38(6-44)$ & $+27(5-32)$ \\
\hline & & & & & & & $+19(6-25)$ & \\
\hline \multirow{3}{*}{$\mathbf{v}$} & \multirow{3}{*}{$\begin{array}{l}\text { IST } \\
\text { LVP }\end{array}$} & 1 & 3 & 20 & & & & \\
\hline & & $+26(9-35)$ & +19 (9-28) & $+22 \quad(8-30)$ & & & & \\
\hline & & $-2(12-10)$ & $0(7-7)$ & $-2(10-8)$ & & & & \\
\hline \multirow{3}{*}{ VI } & \multirow{3}{*}{$\begin{array}{l}\text { IST } \\
\text { LVP }\end{array}$} & 1 & 2 & 6 & 30 & 37 & & \\
\hline & & $+12(6-18)$ & $+14(5-19)$ & $+15(9-24)$ & $+7(10-17)$ & $+24(7-31)$ & & \\
\hline & & $+10(6-16)$ & $+10(6-16)$ & $+6(7-13)$ & & & & \\
\hline \multirow{3}{*}{ VII } & \multirow{3}{*}{$\begin{array}{l}\text { IST } \\
\text { LVP }\end{array}$} & $\mathbf{0}$ & 2 & 4 & & & & \\
\hline & & $+18(11-29)$ & $+16(11-27)$ & $+29(3-32)$ & & & & \\
\hline & & $+9(11-20)$ & $+6(13-19)$ & $-3(17-14)$ & & & & \\
\hline \multirow{3}{*}{ VIII } & \multirow{3}{*}{$\begin{array}{l}\text { IST } \\
\text { LVP }\end{array}$} & 17 & 19 & 39 & 46 & 53 & 70 & \\
\hline & & $+3(10-13)$ & $+6(5-11)$ & $+15(10-25)$ & $+14(8-22)$ & $+13(9-22)$ & $+15 \quad(6-21)$ & \\
\hline & & & & $+18 \quad(4-22)$ & $+17(6-23)$ & $+15 \quad(4-19)$ & $+13(5-18)$ & \\
\hline
\end{tabular}

The two tests were performed on the same day. The plasma cortisol levels during each test are shown in $\mu \mathrm{g} . / 100 \mathrm{ml}$. plasma as the increment during the test, followed by the resting level and maximum stimulated level in parentheses. The patient numbers correspond to those in Fig. 1.

hypoglycaemia and lysine vasopressin may imply that different hypothalamic areas are involved and are affected differently by ACTH therapy.

These observations are of academic interest, but further questions must be answered if they are to be translated into practical significance for the patient. First, since no value to the patient derives from the demonstration of a normal response to hypoglycaemia, it is important to determine whether this reflects his ability to respond to other stresses, such as surgery or trauma. Some observations are available from others as well as ourselves: patients receiving ACTH therapy, when subjected to surgery, have produced increased plasma steroid levels (Marks, Donovan, Duncan, and Karger, 1959; Amatruda, Hollingsworth, D'Esopo, Upton, and Bondy, 1960). We have studied this problem more extensively, and have shown that, in four patients receiving ACTH treatment who underwent five surgical operations, there was a normal plasma cortisol response during operation, which matched the maximum response obtained in these patients by previously infusing supramaximum doses of
ACTH. It was concluded therefore that the response to hypoglycaemia could be taken as a useful and meaningful indication of the patient's ability to respond to other more important types of stress.

Secondly, the problem arises why occasional patients show what may be, in the light of the work reported here, transient suppression of HPA function. It may be significant that the studies in which suppression of metyrapone responses were reported (Plager and Cushman, 1962) were essentially short-term, or that ACTH was given twice daily. In our experience, patients will tolerate twice daily injections without suppression of HPA function, and studies of this aspect are still in progress. We have also noted what appears to be transient suppression, in that continued treatment overcame it, in our one patient (VIII, Fig. 1) who showed this phenomenon. How common this may be, or what conditions it, since it does not occur regularly, is unknown.

Thirdly, the fundamental problem why patients receiving ACTH treatment maintain HPA responsiveness remains unsolved. Since plasma cortisol 
Table II Results of serial insulin (IST) and lysine vasopressin (LVP) tests in patients who had received corticosteroid therapy before $A C T H$

\begin{tabular}{|c|c|c|c|c|c|c|c|c|c|}
\hline Patient & Test & $\begin{array}{l}\text { Period on } \\
\text { steroids }\end{array}$ & \multicolumn{7}{|c|}{ Period on ACTH (wks) } \\
\hline \multirow{3}{*}{$\mathbf{I}$} & \multirow{3}{*}{$\begin{array}{l}\text { IST } \\
\text { LVP }\end{array}$} & 156 & 3 & 9 & 15 & 24 & & & \\
\hline & & $+7(6-13)$ & $+15(5-20)$ & $+15(5-20)$ & $+15(4-19)$ & $+12(5-17)$ & & & \\
\hline & & $+4(4-9)$ & $+2(6-8)$ & $+4(5-9)$ & $+1(4-5)$ & $0(3-3)$ & & & \\
\hline \multirow{3}{*}{ II } & \multirow{3}{*}{$\begin{array}{l}\text { IST } \\
\text { LVP }\end{array}$} & 520 & 2 & & & & & & \\
\hline & & $+5(5-10)$ & $+14(10-24)$ & & & & & & \\
\hline & & $+1(9-10)$ & & & & & & & \\
\hline \multirow{3}{*}{ III } & \multirow{3}{*}{$\begin{array}{l}\text { IST } \\
\text { LVP }\end{array}$} & 156 & 1 & 3 & 10 & 15 & 48 & & \\
\hline & & $+16(10-26)$ & $+18(13-31)$ & $+20(10-30)$ & $+22(12-34)$ & $+23(12-35)$ & $+24(4-28)$ & & \\
\hline & & $+5(11-16)$ & $+11(14-25)$ & $+14(13-27)$ & $+7(10-17)$ & $+12(13-25)$ & $+8(8-16)$ & & \\
\hline \multirow{3}{*}{ IV } & \multirow{3}{*}{$\begin{array}{l}\text { IST } \\
\text { LVP }\end{array}$} & 13 & 4 & & & & & & \\
\hline & & $+4(2-6)$ & $+24(9-33)$ & & & & & & \\
\hline & & $+2(2-4)$ & $+7(14-21)$ & & & & & & \\
\hline \multirow{3}{*}{$\mathbf{V}$} & \multirow{3}{*}{$\begin{array}{l}\text { IST } \\
\text { LVP }\end{array}$} & 156 & 2 & 3 & 8 & 15 & 20 & & \\
\hline & & $+11(2-13)$ & $+28 \quad(7-35)$ & $+32(6-38)$ & $+15(6-21)$ & $+7(16-23)$ & $+9(12-21)$ & & \\
\hline & & & $+1(7-8)$ & $-4(15-11)$ & $+15(5-20)$ & $+12(7-19)$ & $+4(7-11)$ & & \\
\hline \multirow{3}{*}{ VI } & \multirow{3}{*}{$\begin{array}{l}\text { IST } \\
\text { LVP }\end{array}$} & 25 & 3 & 9 & 15 & 22 & 29 & 39 & 46 \\
\hline & & $+9(8-17)$ & $+11(7-18)$ & $+15 \quad(7-22)$ & $+4(13-17)$ & $+7(4-11)$ & $+4(11-15)$ & $+7(11-18)$ & $+4(14-18)$ \\
\hline & & $+5(18-13)$ & $-2(7-5)$ & $-2(12-10)$ & $0(10-10)$ & $0(12-12)$ & & & \\
\hline
\end{tabular}

The two tests were performed on the same day. The plasma cortisol levels during each test are shown in $\mu \mathrm{g}$./100 ml. plasma as the increment during the test, followed by the resting level and maximum stimulated level in parentheses. The patient numbers correspond to those in Fig. 2 .

levels may be considerably raised after an ACTH injection for as much as 10 to 15 hours in each 24 hours using some preparations, it would have been predicted that, as with corticosteroids, suppression would ensue. Others (Bacon and others, 1968) have considered this point and have drawn attention to some possible explanations.

The dose of ACTH employed is clearly relevant to this problem. Since small doses of the order of $5 \mathrm{mg}$. prednisolone daily are tolerated by some patients without marked suppression of HPA function, then equally, doses of ACTH which produce equivalent amounts of cortisol by adrenal stimulation may also be less likely to cause suppression. This explanation seems unlikely to apply to our cases; the doses of ACTH employed varied from 15 to 30 units daily, and from their clinical efficacy and on the basis of the daily excretion of 17-hydroxycorticosteroids, it was estimated that these doses were equivalent to $7 \cdot 5$ to $15 \mathrm{mg}$. prednisolone daily. In our experience this daily dose of steroid invariably produces marked suppression of HPA function.

A further possible explanation arises from the mode of action of ACTH. Since the pattern of plasma cortisol levels after ACTH stimulation differs from that seen after oral corticosteroid therapy, it is conceivable that the different pattern is relevant to the failure of ACTH to cause HPA suppression. However, in attempts to mimic this pattern using slow-acting cortisol preparations, rapid suppression occurred. Alternatively, one could conjecture that the time of ACTH treatment might be related to the lack of suppression. Thus Bacon and others (1968) have suggested that, since ACTH is given once daily, there is a period in which the plasma cortisol levels are low, thus protecting the HPA from suppression. We feel that this is unlikely to be the explanation. In our experience so far, even those patients who receive therapeutic doses of prednisolone only once in 48 hours do not invariably avoid suppression of HPA function.

It is feasible to suppose that the time of injection may be significant. Evening injections of ACTH would tend to produce a high plasma cortisol level at a time when endogenous ACTH release normally occurs. In our experience, this too is not an important factor, and patients receiving evening therapy retained HPA responsiveness like those receiving morning therapy (Figs. 1 and 2).

It appears then that the various obvious possible explanations to account for the different effects on HPA function of ACTH and steroid therapy are not tenable, and one is left with the assumption 
that the ACTH itself is playing some other role besides stimulating the adrenal cortex to produce cortisol. It has been shown experimentally in animal studies that treatment with corticosteroids causes depletion of pituitary stores of ACTH, whereas ACTH treatment causes an approximate doubling of ACTH stores (Kitay, Holub, and Jailer, 1959). In these studies it was also found that experimental stress caused less depletion of pituitary ACTH in the ACTH-treated animals, and also less depletion of adrenal ascorbic acid, and it was therefore concluded that ACTH treatment had caused inhibition of endogenous ACTH release. It does not follow that similar effects occur in man; indeed we believe that our observations illustrate that the ability to release ACTH in response to stress is usually retained in ACTH-treated subjects. Nevertheless, it may be that the explanation for the different effects of ACTH and steroid therapy on HPA function should be sought at pituitary level.

Finally, the role of other steroids released by ACTH from the adrenal may be relevant and remains to be explored. It is marginally possible that dehydroepiandrosterone or androstenedione, for example, may condition or ameliorate the affects of cortisol on the hypothalamus or pituitary-such studies are in hand.

\section{Summary}

Fourteen patients with active chronic rheumatic disease were treated by long-term daily cortico- trophin therapy. This effectively controlled their disease. At regular intervals during treatment, hypothalamic-pituitary-adrenal (HPA) function was investigated by studying the plasma cortisol response to induced hypoglycaemia and to lysine-8-vasopressin.

The majority of patients who had not previously received corticosteroids maintained normal, or only marginally subnormal, responses to insulin hypoglycaemia, although one patient showed HPA suppression during the first few months of ACTH therapy which disappeared later without change of treatment. Those patients who had been treated with corticosteroids rapidly achieved and maintained normal, or occasional marginally subnormal, responses on conversion to corticotrophin therapy. There was, however, no correlation when results of insulin stress tests were compared with those of lysine-8-vasopressin tests.

It is concluded, therefore, that corticotrophin therapy offers the significant advantage of preserving HPA responsiveness to stress, in contrast to corticosteroid therapy. The possible reasons for this difference are discussed.

This study was carried out with the aid of grants from the Arthritis and Rheumatism Council for Research and from the Edgar Lawley Foundation, which we gratefully acknowledge. We have also received assistance from Armour, Crookes, and Organon Laboratories to whom our thanks are due, and we are grateful to Mrs. Joy Chow for assistance with preparing the manuscript.

\section{References}

Amatruda, T. T., Hollingsworth, D. R., D’Esopo, N. D., Upton, G. V., ANd Bondy, P. K. (1960) J. clin. Endocr., 20, 339 (A study of the mechanism of the steroid withdrawal syndrome. Evidence for integrity of the hypothalamic-pituitary-adrenal system).

Bacon, P. A., Daly, J. R., Myles, A. B., and Savage, O. (1968) Ann. rheum. Dis., 27, 7 (Hypothalamo-pituitaryadrenal function in patients on long-term adrenocorticotrophin therapy).

Brostoff, J., JAMES, V. H. T., AND LANDON, J. (1968) J. clin. Endocr., 28, 511 (Plasma corticosteroid and growth hormone response to lysine-vasopressin in man).

Daly, J. R., Myles, A. B., Bacon, P. A., Beardwell, C. G., And Savage, O. (1967) Ann. rheum. Dis., 26, 18 (Pituitary adrenal function during corticosteroid withdrawal in rheumatoid arthritis).

Greenwood, F. C., Landon, J., ANd Stamp, T. C. B. (1966) J. clin. Invest., 45, 429 (The plasma sugar, free fatty acid, cortisol and growth hormone response to insulin: I. In control subjects).

Holub, D. A., WAllace, E. Z., AND Jailer, J. W. (1960) J. clin. Endocr., 20, 1294 (Pituitary adrenocorticotrophin (ACTH) reserve in man following prolonged ACTH therapy).

Jasani, M. K., Boyle, J. A., Greig, W. R., Dalakos, T. G., Browning, M. C. K., Thompson, A., and BuChanAN, W. W. (1967) Quart.J. Med., 36, 261 (Corticosteroid-induced suppression of the hypothalamo-pituitary-adrenal axis: observations on patients given oral corticosteroids for rheumatoid arthritis).

KitAY, J. I., Holub, D. A., AND JAILER, J. W. (1959) Endocrinology, 64, 475 (Inhibition of pituitary ACTH release, an extra-adrenal action of exogenous ACTH).

LANDON, J., WynN, V., JAMES, V. H. T., AND Wood, J. B. (1965) J. clin. Endocr., 25, 602 (Adrenal response to infused corticotropin in subjects receiving glucocorticoids).

Livanou, T., Ferriman, D., AND James, V. H. T. (1967) Lancet, 2, 856 (Recovery of hypothalamo-pituitary-adrenal function after corticosteroid therapy).

Marks, L. J., Donovan, M. J., Duncan, F. J., AND Karger, R. (1959) J. clin. Endocr., 19, 1458 (Adrenocortical response to surgical operations in patients treated with corticosteroids or corticotropin prior to surgery). 
Plager, J. E. ANd Cushman, P. (1962) Ibid., 22, 147 (Suppression of the pituitary-ACTH response in man by administration of ACTH or cortisol).

Ropes, M. W., Bennett, G. A., Cobb, S., Jacox, R., And Jessar, R. A. (1959) Ann. rheum. Dis., 18, 49 (Diagnostic criteria for rheumatoid arthritis. 1958 revision).

Savage, O., Copeman, W. S. C., Chapman, L., Wells, M. V., and Treadwell, B. L. J. (1962) Lancet, 1, 232 (Pituitary and adrenal hormones in rheumatoid arthritis).

SOlem, J. H. AND BRINCK-JohNSEN, T. (1961) Acta med. scand., 170, 89 (Indirect estimation of pituitary corticotrophin reserve in man by use of an adrenocortical $11 \beta$-hydroxylase inhibitor (SU-4885 Ciba)).

TownSEND, J. AND JAMES, V. H. T. (1968) Steroids, 11, 497 (A semi-automated fluorimetric procedure for the determination of plasma corticosteroids).

Treadwell, B. L. J., Savage, O., Sever, E. D., and Copeman, W. S. C. (1963) Lancet, 1, 355 (Pituitary-adrenal function during corticosteroid therapy).

\section{RÉSUME}

\section{L'effet de la thérapie par la corticotrophine sur la fonction pituito-surrénale}

Quatorze malades atteints de rhumatisme chronique évolutif ont été traités journellement par la thérapie à la corticotrophine à long terme. Ce traitement a maîtrisé efficacement leur maladie. $\grave{A}$ des intervalles réguliers pendant le traitement, la fonction hypothalamo-pituitosurrénale (HPS) a été étudiée en relation du comportement du cortisol plasmatique lors de l'hypoglycémie induite et du test à la lysine-8-vasopressine.

La majorité des malades qui n'avait pas reçu de corticostéroïdes avait montré une action normale ou seulement légèrement sous-normale à l'hypoglycémie insulinique, quoiqu'un malade eut montré une suppression de l'axe HPS pendant les quelques premiers mois de la thérapie par ACTH qui disparaissait plus tard sans aucun changement du traitement. Ces malades qui avaient été traités avec les corticostéroïdes ont atteint et maintenu la normale ou occasionnellement la sousnormale quand ils ont passé au traitement à la corticotrophine. Il n'y avait, cependant, aucune corrélation quand les résultats des tests à l'insuline étaient comparés aux tests de lysine-8-vasopressine.

Ainsi il a été conclu que la thérapie à la corticotrophine offre un avantage significatif en préservant la réaction HPS au stress, en contraste à la thérapie avec les corticostéroïdes. Les raisons possibles de cette différence sont discutées.

\section{SUMARIO}

Efecto de la terapia de corticotropina en la función pituito-suprarrenal

Catorce pacientes con enfermedad reumática crónica activa fueron tratados mediante terapia de corticotropina diaria, durante largo tiempo. Esto controló eficazmente la enfermedad. A intervalos regulares, durante el tratamiento, se investigó la función hipotalámo-pituito-suprarrenal (HPS) por medio de un estudio de la reacción del cortisol del plasma a la hipoglucemia inducida y a la lisina-8-vasopresina.

La mayoría de los pacientes que no habían recibido antes corticosteroides mantuvieron reacciones normales, o marginalmente subnormales, ante la hipoglucemia insulínica, si bien un paciente reveló supresión del eje HPS durante los primeros meses de la terapia con ACTH, supresión que desapareció más tarde sin cambiar el tratamiento. Los pacientes que habían sido tratados con corticosteroides alcanzaron rápidamente, y mantuvieron, reacciones normales, o en ciertos casos marginalmente subnormales, al cambiar a la terapia de corticotropina. No hubo, sin embargo, correlación cuando los resultados de las pruebas con insulina fueron comparados con las pruebas con lisina-8-vasopresina.

Así pues, se llega a la conclusión de que la corticotropina ofrece la ventaja significativa de preservar la reacción del eje HPS al strêss, en contraste con la terapia de corticosteroides. Se discuten las posibles razones de esta diferencia. 